\title{
Performance Investigation of Quasi Z Source Inverter (QZSI) Fed Induction Motor (IM) Drive System with bGWO-RDF Technique
}

\author{
Shunmugakani $P^{1, *}$, D. Kirubakaran ${ }^{2}$ \\ ${ }^{1}$ Sathyabama Institute of Science and Technology, Chennai, Tamil Nadu, India \\ ${ }^{2}$ St. Joseph's Institute of Technology, Tamil Nadu, India
}

Received November 12, 2019; Revised December 23, 2019; Accepted December 27, 2019

Copyright $\bigcirc 2020$ by authors, all rights reserved. Authors agree that this article remains permanently open access under the terms of the Creative Commons Attribution License 4.0 International License

\begin{abstract}
In this dissertation, a hybrid strategy is intended for performance investigation of Quasi Z Source Inverter (QZSI) fed Induction motor (IM) drive system. The hybrid strategy is the fusion of both the binary version of grey wolf optimization (bGWO) and random decision forest (RDF) and commonly called as bGWO-RDF technique. The main contribution of the dissertation is to control the QZSI for enhancing the stability and the performance of IM drive system using the proposed hybrid strategy. The input of the proposed strategy is the speed and three phase current of IM. With the help of input parameters like actual speed and reference speed of IM, the PI controller gain parameters are optimized using bGWO technique. In order to train the RDF, the PI controller output like reference quadrature axis current and actual quadrature axis current is chosen. By utilizing the RDF, the reference three phase current is generated. By utilizing the actual and reference three phase current, the control pulses are generated at the final stage. Finally, the proposed technique is executed in the MATLAB/Simulink working platform. The effectiveness of the proposed is compared with various existing techniques such as ANN, PSO, PSO-SVM and GSA-SVM. The effectiveness of the proposed and other existing techniques is analyzed in terms of ripples and harmonics reduction, rise time, settling time and steady state error. Furthermore, the statistical analysis is also performed and compared with other existing techniques. The comparison result reveals that the total harmonic distortion (THD) is decreased and the oscillation period of the stator current, torque and speed are eliminated.
\end{abstract}

Keywords QZSI, IM, Speed and Three Phase Current, Control Pulses, Ripples and Harmonics Reduction, Rise Time, Settling Time and Steady State Error

\section{Introduction}

Z-source inverter is a buck-boost inverter that has a wide range of obtainable voltage. To defeat the issue in conventional VSI and CSI, it cannot implement as some obtainable voltage in Z- source inverter. Z-Source inverter has been developed in different control methods hence the Z-Source inverter was established in 2002 [1]. Quasi-Z-source inverters (qZSI) were proposed in 2008 [2]. Based on ceaseless input current and large EMI defense, QZSI implements the wide settlement freedom. Simple composition and ceaseless input current, the comfortable structure consists of three phase source inverters is generally used in quasi-ZSI (qZSI) [3-7]. To maintain the benefits in qZSI competent for renewable power applications some examples are solar panels, fuel cells, wind power generators, etc. [8-11] and electric drive applications [12].

Different modes of operation in literature consist of ZSI and qZSI have been considered in [13-15]. To control the duty cycle of gadget switch in circuit, the modulation width of pulse in qZSI [16] handovers the AC voltage. To obtain any craved output voltage ac, the capability of Quasi Z Source system, implement driving conditions through voltage drops and reduce motor ratings to obtain the necessary power permits it to be used for flexible speed drive systems [17]. Induction motor consists of three phases, they are great extensively used in different industrial applications due to the consecutive self-starting properties; extinction of a starting device; robust construction; greater power factor and better speed regulation.

To control the speed different methods are used such as, stator voltage control, frequency control, stator voltage, frequency control and rotor voltage control. Due to the plentiful methods, variable frequency application takes as 
more benefits example simple method implement control the speed behind and speed rate up. Here the frequency variable is used to control the speed and motor induction is established for dissection [18]. To control the speed of motor conventional PI controller can control the frequency inverter. Moreover, the steady state achievement outcomes are rarely utilized to conventional PI model. Based on transient achievements, these methods cannot give better outcomes such as saturation effects, parameter variations, load disturbances, temperature variations, etc. [19]. To compare the expert system and fuzzy logic, it is the most kind in the generic form of AI due to artificial neural network or neural network (ANN). To control the speed of induction motor ANN is considered to many researchers [20]. In this dissertation, a hybrid strategy is intended for performance investigation of Quasi Z Source Inverter (QZSI) fed Induction motor (IM) drive system. The hybrid strategy is the fusion of both the binary version of grey wolf optimization (bGWO) and random decision forest (RDF) and commonly called as bGWO-RDF technique. The main contribution of the dissertation is to control the QZSI for enhancing the stability and the performance of IM drive system using the proposed hybrid strategy. Rest of the dissertation is organized as follows: section 2 depicts the recent research work and its background. Section 3 explains the quasi Z-Source inverter (QZSI) fed IM with the aid of proposed strategy. Section 4 explains the simulation results and discussion for the performance analysis of QZSI fed IM drive system. Section 5 concludes the dissertation.

\section{Recent Research Works: A Brief Review}

In literature review, different research works have occurred earlier based on the importance of quasi z-source inverter fed induction motor drive utilized different methods and conditions. Few methods were reported here.

S. Dong et al. [21] have established a Z-Source drive PMSM control system to adjustable DC-link voltage is used to perform motor system capability. Working region of torque and PMSM speed utilized to maximize as both flux-weakening and $\mathrm{DC} / \mathrm{DC}$ voltage rising stages can also be implemented. M. Muhammad et al. [22] illustrated a newly presented hybridization storage energy model for quasi-Z-source inverter spreader in induction drive motor. The goal of this work was used to stress the current on battery by merged with super capacitor formed as hybrid storage energy due to the bidirectional integration of $\mathrm{DC} / \mathrm{DC}$ converter to the inverter. In an induction motor $5 \mathrm{~kW}$ drive system is decorated, applied and simulated to MATLAB/Simulink surroundings, the field-oriented control was used to classify the importance of drive system of induction motor and newly presented model of hybrid storage energy system based on acceleration/regenerative braking. A dynamic evolution control (DEC)-due to quasiZ-source inverter (QZSI) implemented five different phases of induction motor (IM) drive system based on nonideal voltage supply conditions was established by A. K. Panda and R. Pandey [23]. Multiphase drives are the most essential methods for sensitive applications, due to the form of disturbances as voltage sag and serious impact as interruption. QZSI allows major benefits among conventional inverter; some examples are boost in output direct current (DC) voltage (VO), utilization of shootthrough state of inverter switches, and delay time avoidance between switches of inverter's every leg. Thus the benefits are mostly used with presented DEC (a nonlinear control function) due to duty cycle " $D$ " generation model. " $\mathrm{D}$ " integrated vector modulation space (VMS) scheme for direct torque control (DTC) of fiveschemes in IM drive.

Induction drive motor system was used to control with Z-source inverter was established by S. Mythili and K. Thiyagarajah [24]. To perform the induction motor (IM) used to consolidate with hybrid technique based on gravitational search algorithm (GSA) and support vector machine (SVM). With the help of presented hybrid technique, the uniqueness of study utilized to control the inverter as Z-Source to perform the balance of IM drive system. Consequently, the total harmonic distortion (THD) was minimized and period of oscillation in current stator, torque and eliminated speed. Input of the presented technique was speed of motor and speed of reference. In axis current, the quadrature reference of presented method shows output. To obtain the reference quadrature axis current, PI controller is utilized to get an optimal outcome. To predict the pulse control of voltage source inverter SVM was utilized. To generate the pulse control efficiency, a three phase reference current utilized. To implement the destination reference, SVM is trained as three-phase reference current based on input motor quadrature axis current and reference quadrature axis current. M. Sharma and M. Lalwani et al. [25] have evaluated and complemented as ZSI, utilized to the speed of boundary induction motor. Ripple of Z-source elements, output voltage source, current are verified due to modulation index and frequency switch with harmonic profile. Main goal was utilized to evaluate the performance technique for harmonic reduction and induction motor.

\subsection{Background of the Research Work}

Review of recent research work displays, for controlling Z-source inverters fed as IM drives, an optimized harmonic presentation observe as various PWM control schemes has been announced based on the effort of lower switch loss. Although this method has some variations in characteristics, they are generally developed by initial firing states to the classical VSI state chains with additional possible states to merge behind low inductance conditions 
of low load. Due to its conceded aggregate results control the voltage gain obtained, which now based on the load, for that generalized was more difficult to control. To reduce the load influence adequate parametric regulation must be completed to decrease the total maximum frequency current fluctuation in the circuit while analyzed with the level of completed charge. While it is to stabilize the gain parametric tuning may not reject the low cut off current at the DC source in which the force mortifies the characteristics response of the source. To overcome the problem of this traditional power inverter topology, a high efficiency Z-source inverter is used.

\section{Quasi Z-Source Inverter Fed Induction Motor (IM) with the Proposed Strategy}

In this section, Quasi Z-Source Inverter (QZSI) fed IM with the aid of proposed strategy is presented. Fig 1 depicts the proposed configuration of QZSI fed with IM. QZSI is worked under two different operating modes they are: shoot-through and non shoot-through state. Benefits of
QZSI are the voltage buck and boost ability inexpensive. The main theme shows: with the help of proposed technique, QZSI pulses are controlled and subsequently which performs the stability and performance of IM drive system [26]. Fig 1 delineates the control scheme employed in the proposed strategy. In QZSI, the DC power supply is executed for the conversion of DC voltage to the necessary three phase AC voltage. For the operation of IM, the outcome of inverter is utilized. The input of proposed strategy is the speed and three phase current of IM. With the help of input parameters like actual speed of IM and reference speed, PI controller gain parameters are optimized using the binary version of Grey Wolf Optimization (bGWO) technique. In order to train the random decision forest (RDF), the PI controller output like reference quadrature axis current and actual quadrature axis current is chosen. The reference three phase current has been obtained, by utilizing the random decision forest (RDF). By the actual and reference three phase current, the pulse control is accomplished at the final stage. In order to operate the insulated gate bi-polar transistor (IGBT) the control pulses are used. In the following subsection, QZSI modelling is given.

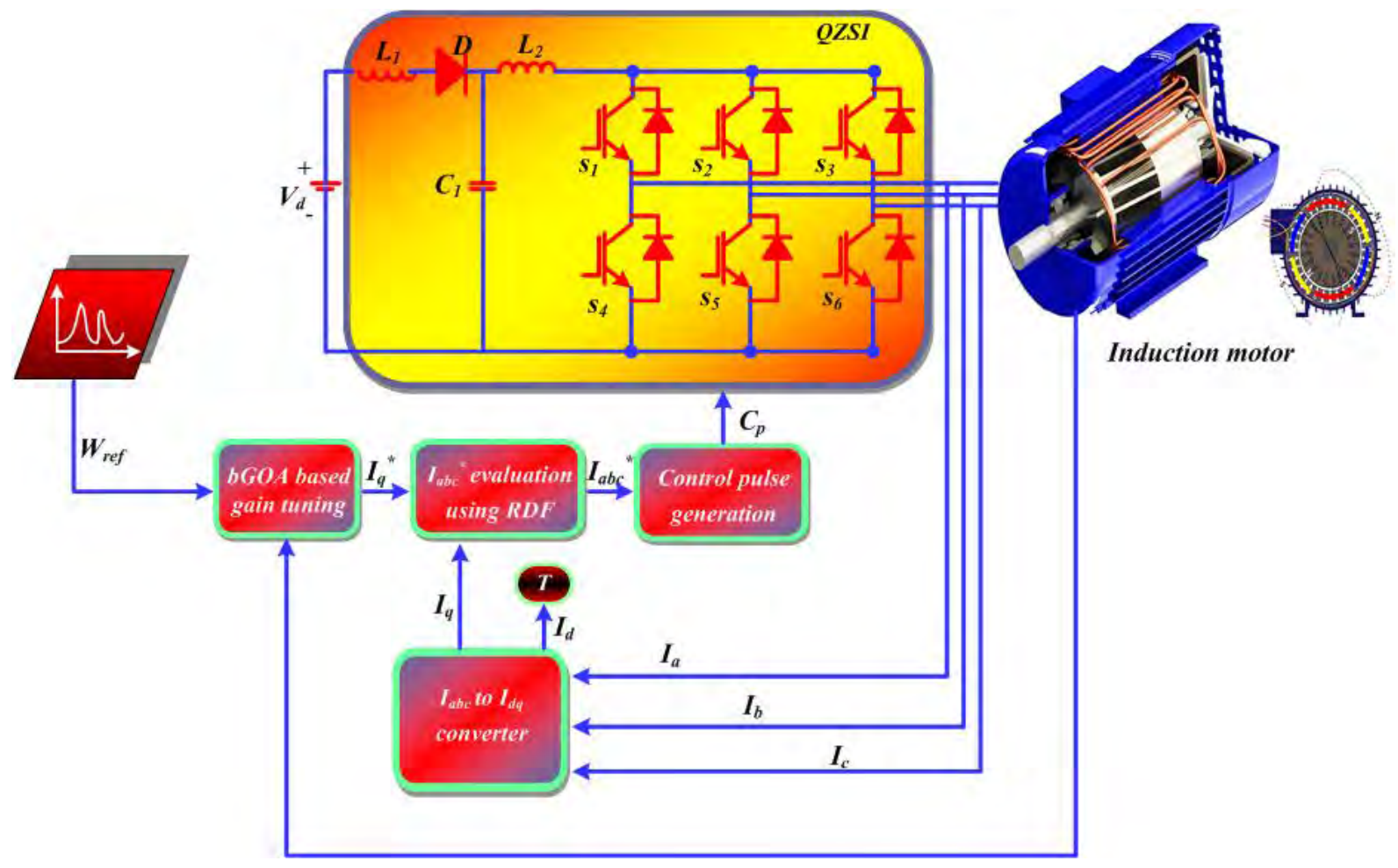

Figure 1. Proposed configuration of QZSI fed IM 


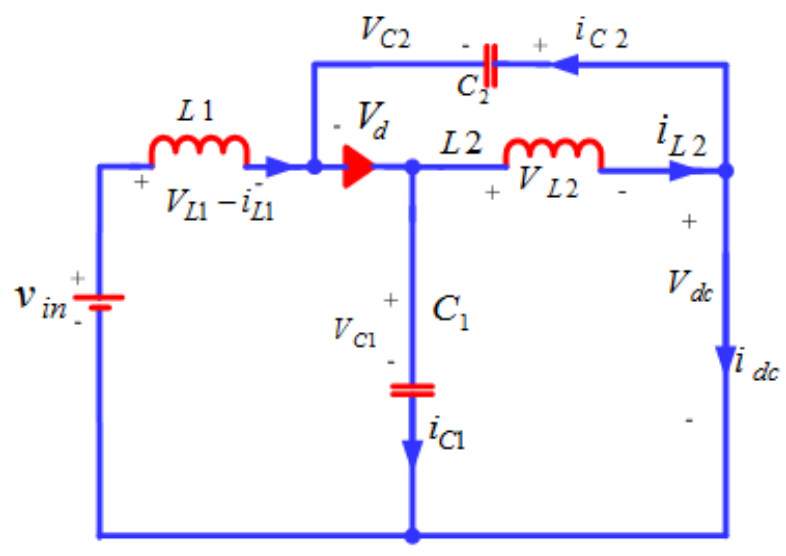

(a)

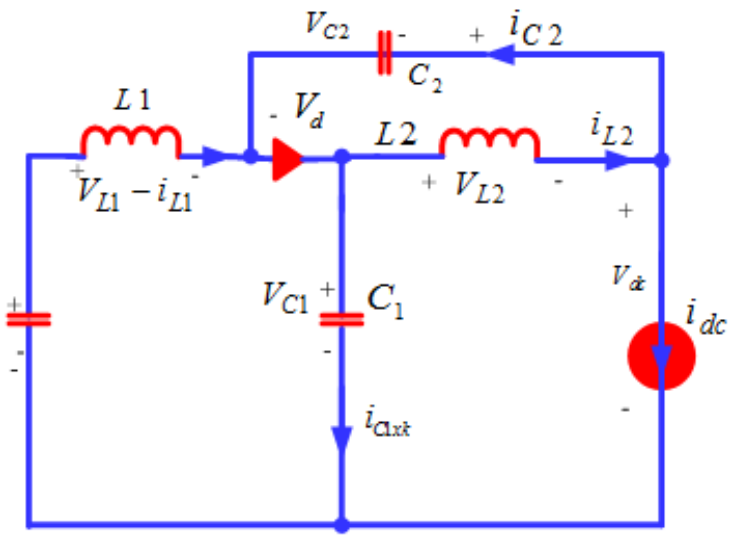

(b)

Figure 2. QZSI (a) Shoot through state (b) non shoot through state

\subsection{QZSI Modeling}

The modified version of conventional Z-source inverter is the QZSI which is the type of unique stage power converter. In QZSI, signals from source is separated and regulated, which helps to control fluctuations of voltage, reduces the switching ripples and reduce stress in the source. In QZSI based on switching conditions two states of operations such as shoot through state and non shoot-through state [27]. In Fig 2(a) and (b) shows that the equivalent circuit of shoot through state and non-shoot through state. In shoot through state, the switches present in circuit are active state and available components like inductors and capacitors are actively performed in short duration. During non-shoot through state, load and source are directly connected mode through switches present in the circuit, which ensures that QZSI as current source at this time.

If shoot through state the duty cycle can be defined as,

$$
D_{c y}=t_{s t} / t_{s}
$$

where $D_{c y}$ represented as duty cycle. The steady state can be described as follows.

$$
\begin{aligned}
\frac{V_{C 1}}{V_{i n}} & =\frac{1-D_{c y}}{1-2 D_{c y}} \\
\frac{V_{C 2}}{V_{D C}} & =\frac{D_{c y}}{1-2 D_{c y}}
\end{aligned}
$$

From equation (2) and (3)

$$
\begin{gathered}
\frac{V_{D c y}}{V_{i n}}=\frac{1-D_{c y}}{1-2 D_{c y}}+\frac{D_{c y}}{1-2 D_{c y}}=\frac{1}{1-2 D_{c y}} \\
V_{D c y}=\frac{1}{1-2 D_{c y}} \cdot V_{i m}
\end{gathered}
$$

where $V_{C 1}$ and $V_{C 2}$ are the first and second capacitors, $V_{\text {in }}$ represented as the input source. In order to control the switches of IGBT inverter, the proposed control method is utilized. Here, two algorithms are utilized such as bGWO based optimization of gain and RDF based generation of control pulse. In the following section, the bGWO based optimization of gain is expressed.

\subsection{Optimization of Gain Parameter of PI Controller Using bGWO Technique}

Grey wolf optimizer (GWO) is the most recent bio-inspired optimization technique which imitates the process of hunting process and grey wolves in nature [28]. In this paper, the binary version is performed based on two approaches.

- $\quad$ First Approach: Singular steps toward the first three best solutions are binarized and then the stochastic crossover is performed between the three essential movements to discover the updated binary position of the grey wolf.

- Second Approach: Sigmoidal function is utilized to crush the continuous updated position, at that stochastic threshold point these qualities to discover the updated binary position of the grey wolf.

Two approaches to binary grey wolf optimization (bGWO) are executed to optimize the gain parameter of the PI controller. Here, bGWO optimizes and minimizes the error rate of the IM. Proportional and integral gain parameters must be optimally predicted to achieving the minimum error. The reference quadrature axis current $\left(I_{q}^{*}\right)$ is accomplished and the PI tuning is performed accurately from the optimized parameters. The step by step procedure used to obtain the optimal gain parameters of PI controller is expressed below [29-32],

\subsubsection{Steps of bGWO}

Step 1: Initialization 
In initial step, introduce the random generation of PI controller gain parameters like $K_{p}$ and $K_{i}$.

Step 2: Fitness Evaluation

The fitness function of agents is assessed as their minimum objective function. The fitness function of the ant-lion and ants is figured as takes after:

$$
F_{i}=\operatorname{best}\left(f_{i}^{t}\right)=\min \left(K_{p} e(t)+K_{i} \int_{0}^{t} e(t)\right)
$$

From the above equation, the fitness is evaluated. Once the $K_{p}$ and $K_{i}$ parameters are tuned, the process get optimized.

Step 3: Position Updating

The position updating is done according to the position of the best search agents and the equation is derived as follows,

$$
\vec{x}(t+1)=\frac{\overrightarrow{x_{1}}+\overrightarrow{x_{2}}+\overrightarrow{x_{3}}}{3}
$$

here position of the grey wolf is indicated as $\vec{x}$.

$$
\begin{aligned}
& \overrightarrow{x_{1}}=\left|\overrightarrow{x_{\alpha}}-\overrightarrow{a_{1}} \bullet \overrightarrow{d_{\alpha}}\right| \\
& \overrightarrow{x_{2}}=\left|\overrightarrow{x_{\beta}}-\overrightarrow{a_{2}} \bullet \overrightarrow{d_{\beta}}\right| \\
& \overrightarrow{x_{3}}=\left|\overrightarrow{x_{\gamma}}-\overrightarrow{a_{3}} \bullet \overrightarrow{d_{\gamma}}\right|
\end{aligned}
$$

Here, the first three best solutions in the swarm at given iteration as $\overrightarrow{x_{\alpha}}, \overrightarrow{x_{\beta}}, \overrightarrow{x_{\gamma}}$.

Step 4: Approach 1 (bGWO1)

The formulation of the main updating equation is done by the approach 1 called bGWO1.

$$
x_{i}^{t+1}=\operatorname{crossover}\left(x_{1}, x_{2}, x_{3}\right)
$$

here suitable crossover between solutions $x, y, z$ as crossover $(x, y, z)$, alpha, beta, gamma are the binary vectors which are represented as $x_{1}, x_{2}, x_{3}$.

$$
X_{i}^{s}= \begin{cases}1 & \text { if }\left(X_{\alpha}^{d}+b s t e p_{\alpha}^{s}\right) \geq 1 \\ 0 & \text { otherwise }\end{cases}
$$

here the position vector of the alpha wolf in the dimension $s$ as $X_{\alpha}^{s}$, binary step in dimension $\mathrm{s}$ as $b s t e p_{\alpha}^{s}$. The equation of bstep ${ }_{\alpha}^{s}$ is as follows,

$$
\text { bstep }_{\alpha}^{s}= \begin{cases}1 & \text { if } \text { cstep }_{\alpha}^{s} \geq \text { rand } \\ 0 & \text { otherwise }\end{cases}
$$

here random number as rand, continuous valued step size for dimension $s$ as cstep $_{\alpha}^{s}$ then the equation is as follows,

$$
\begin{gathered}
\text { cstep }_{\alpha}^{s}=\frac{1}{1+e^{-10\left(a_{1}^{s} d_{\alpha}^{s}-0.5\right)}} \\
X_{2}^{s}= \begin{cases}1 & \text { if }\left(X_{\beta}^{s}+\text { bstep }_{\alpha}^{s}\right) \geq 1 \\
0 & \text { otherwise }\end{cases}
\end{gathered}
$$

here the position vector of the beta wolf in the dimension $\mathrm{s}$ as $X_{\beta}^{s}$, binary step in dimension s as bstep $p_{\alpha}^{s}$ the equation of bstep $_{\alpha}^{s}$ is as follows,

$$
\text { bstep }_{\beta}^{s}= \begin{cases}1 & \text { if } \text { cstep }_{\beta}^{s} \geq \text { rand } \\ 0 & \text { otherwise }\end{cases}
$$

here the continuous valued step size for dimension $\mathrm{s}$ as $\operatorname{cstep}_{\beta}^{s}$ and it can be calculated for the sigmoidal function as follows,

$$
\begin{gathered}
\operatorname{cstep}_{\beta}^{s}=\frac{1}{1+e^{-10\left(a_{1}^{s} d_{\beta}^{s}-0.5\right)}} \\
X_{3}^{s}= \begin{cases}1 & \text { if }\left(X_{\gamma}^{s}+\text { bstep }_{\gamma}^{s}\right) \geq 1 \\
0 & \text { otherwise }\end{cases}
\end{gathered}
$$

here the position vector of the delta wolf in the dimension $\mathrm{s}$ as $X_{\gamma}^{s}$, binary step in dimension s as bstep ${ }_{\gamma}^{s}$ and the equation for the bstep $p_{\gamma}^{s}$ as follows,

$$
\operatorname{cstep}_{\gamma}^{s}=\frac{1}{1+e^{-10\left(a_{1}^{s} d_{\gamma}^{s}-0.5\right)}}
$$

In order to crossover a, b, c solutions, a simple stochastic crossover strategy is applied and the equation is given in the following,

$$
X_{s}= \begin{cases}a_{s} & \text { if rand }<\frac{1}{3} \\ b_{s} & \frac{1}{3}<\text { rand }<\frac{2}{3} \\ c_{s} & \text { otherwise }\end{cases}
$$

where the binary values for first, second and third parameter in dimension $\mathrm{s}$ as $a_{s}, b_{s}, c_{s}$, crossover output at dimension s as $X_{s}$. The algorithm 1 for the approach 1 is depicted in the following,

Algorithm 1: Approach 1

Input: Number of grey wolves in the pack Number of iterations for optimization

Output: Optimal grey wolf binary position Best fitness value 
1. Initialize the population of $n$ position of grey wolves randomly

2. Based on the fitness find the $\alpha, \beta, \gamma$ solutions

3. While Stopping criteria not met do

foreach Wolf $_{i} \epsilon$ pack do

Calculate $x_{1}, x_{2}, x_{3}$ using equation (8), (9), and (10)

$x_{i}^{t+1} \leftarrow$ crossover among $x_{1}, x_{2}, x_{3}$ using equation (11)

End

I. Update a, $A, C$

II. Evaluate the individual wolves positions

III. Update $\alpha, \beta, \gamma$

End

Step 5: Approach 2 (bGWO2)

Only this approach the updated position vector of the grey wolf is forced to be as binary. The updating function is reformed as follows,

$$
X_{s}^{t+1}=\left\{\begin{array}{l}
1 \quad \text { if sigmoid }\left(\frac{\overrightarrow{x_{1}}+\overrightarrow{x_{2}}+\overrightarrow{x_{3}}}{3}\right) \geq \text { rand } \\
0 \text { otherwise }
\end{array}\right.
$$

$$
\operatorname{sigmoid}(a)=\frac{1}{1+e^{-10(X-0.5)}}
$$

The algorithm 2 for the approach 2 is depicted in the following,

Algorithm 2: Approach 2

Input: Number of grey wolves in the pack Number of iterations for optimization

Output: Optimal grey wolf binary position Best fitness value

1. Initialize the population of $n$ position of grey wolves randomly

2. Based on the fitness find the $\alpha, \beta, \gamma$ solutions

3. While Stopping criteria not met do foreach Wolf $_{i} \epsilon$ pack do

Update wolfi position to a binary position based on equation (21)

End

I. Update a, $A, C$

II. Evaluate the individual wolves positions

III. Update $\alpha, \beta, \gamma$

End

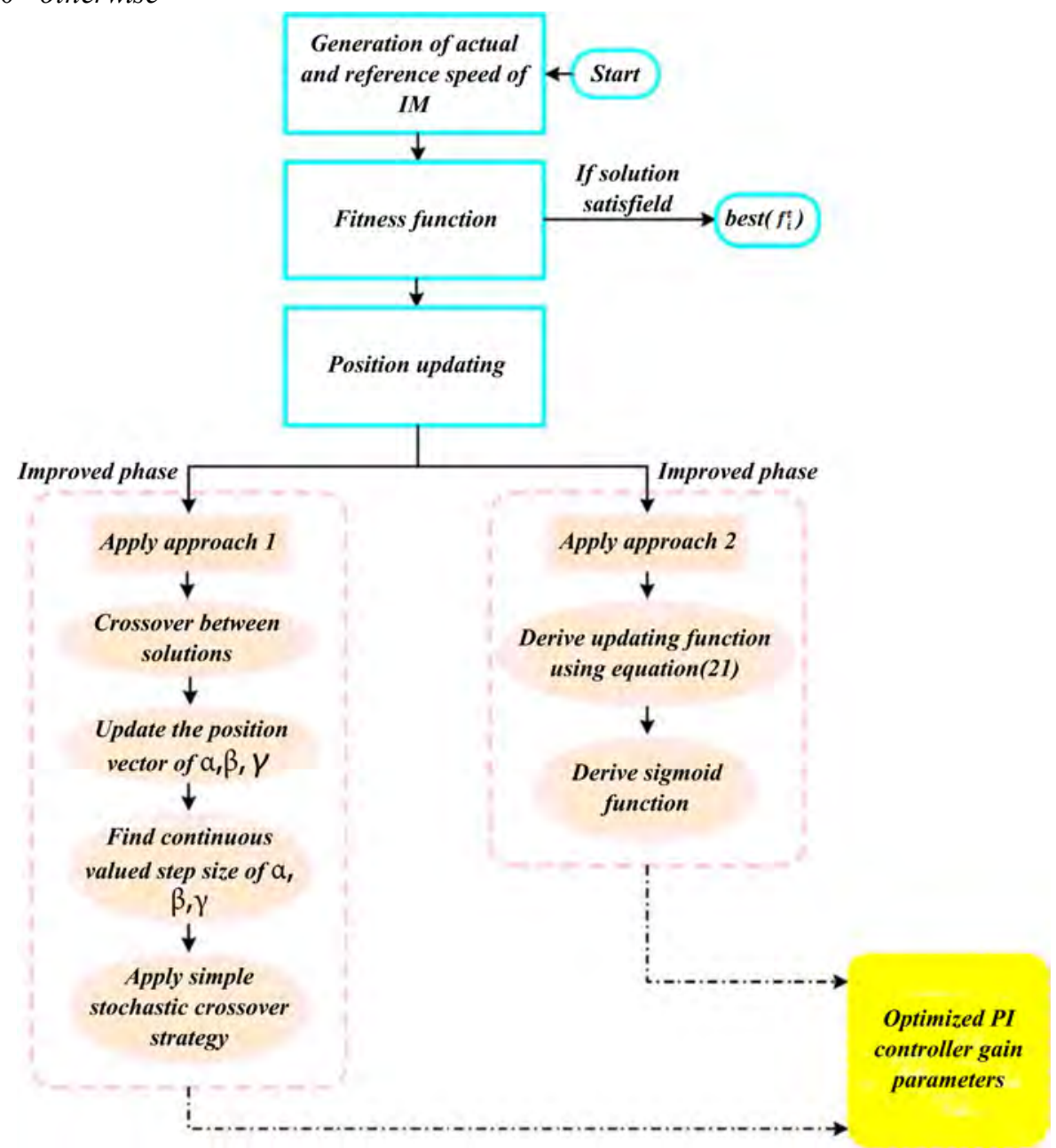

Figure 3. Process of bGWO technique 
Step 6: Termination

Until the previous section is repeated from steps 2 to 6 the maximum iteration is reached. Fig 3 shows the process of the proposed bGWO algorithm. The bGWO algorithm provides optimal gain parameters once the previous process is completed and then applied to the PI controller. The output of PI controller is the quadrature axis current and it is the RDF technique input. Through inputs such as reference and the actual current of the quadrature axis $I_{q}^{*}$ and $I_{q}$, and the RDF predicts the three phase reference current $I_{a b c}^{*}$. The point by point representation of the RDF based on control pulses generation is examined in subsection 3.3.

\subsection{Generation of Control Pulses Using RDF Technique}

Random Decision Forest (RDF) is a set of machine learning procedure in the process of prediction [36]. In RDF it consists of two hyper parameters [33-37]: in the subset, the number of divisions in every node and the number of trees in the forest. In the proposed technique the RDF optimally predicts control signals with less error. By using the inputs as the reference current and real quadrature axis current, the RDF technique predicts the three phase reference current. The RDF input layer consists of the reference and actual quadrature axis current. The RDF output layer consists of three phase reference current. The step by step process of RDF is shown below.

\subsubsection{Steps of RDF}

Step 1: In RDF, by the reference and actual quadrature axis current, the parameters of the inverters are prepared.

Step 2: RDF makes the combination of decision trees in the classifier technique. Initially, to make the decision tree numbers of trees in the forest are considered, it creates $b=\left\{a_{1}(t), a_{2}(t), \cdots a_{n}(t)\right\}$ a combination, and each of these is known as bootstrap samples.

Step 3: Based on the input and output target of RDF is trained. Some input variables through each tree in this technique are passed and generate output. On this set based on the maximum vote the final optimal result is obtained.

Step 4: In the prediction process by evaluating the input variables an importance of the RDF are ranked. The variable significance is detected by comparing the prediction error with the data term Out-Of-Bag. Different datasets are managed in order to enhance the RDF model by each sample. The number of splits is randomly selected to generate the binary rule in each node. To best split prediction mean square error (RMSE) is created in the tree for every split the root.

Step 5: For increasing the prediction accuracy the variable importance is measured. These errors are averaged during the period of fitting over the forest and each data error is calculated on-of-bag. After the training process each data is computed over all trees, the difference in out-of-bag (OOB) error before and after the permutation. The importance of the variable is calculated in the following equation,

$V_{i}^{(\text {tree })}=\frac{1}{t}\left(\frac{\sum_{X A \in \beta^{(\text {trree })}} i\left(L_{B}=p_{c}^{\text {tree }}\right)-\sum_{X A \in \phi^{(\text {trree }}} i\left(L_{B}=p_{c, N Z}^{\text {tree }}\right)}{\operatorname{pec}^{(\text {tree })}}\right)$

where OOB trace sample for a peculiar tree as $p e c^{(\text {tree })}$, the tree number is represented by tree, the total number of tree is represented by $t$, predicted classes for each trace sample as $p_{c}^{\text {(tree) }}$ and $p_{c, \pi z}^{(\text {tree })}$, the value of the sample is represented by $x_{A}, A, B$ is the number of trace samples per tree exit and number of trace sample per tree in the forest. To give the appropriate reference values, the RDF is ready once the previous process is finished. Finally, the RDF output is transformed as appropriate control pulses. Fig 4 represents the generation control signals using RDF technique. By then, the proposed technique is tested under the MATLAB/Simulink platform and compared to the other solution techniques. The result of simulation and discussion are shown in Section 4. 


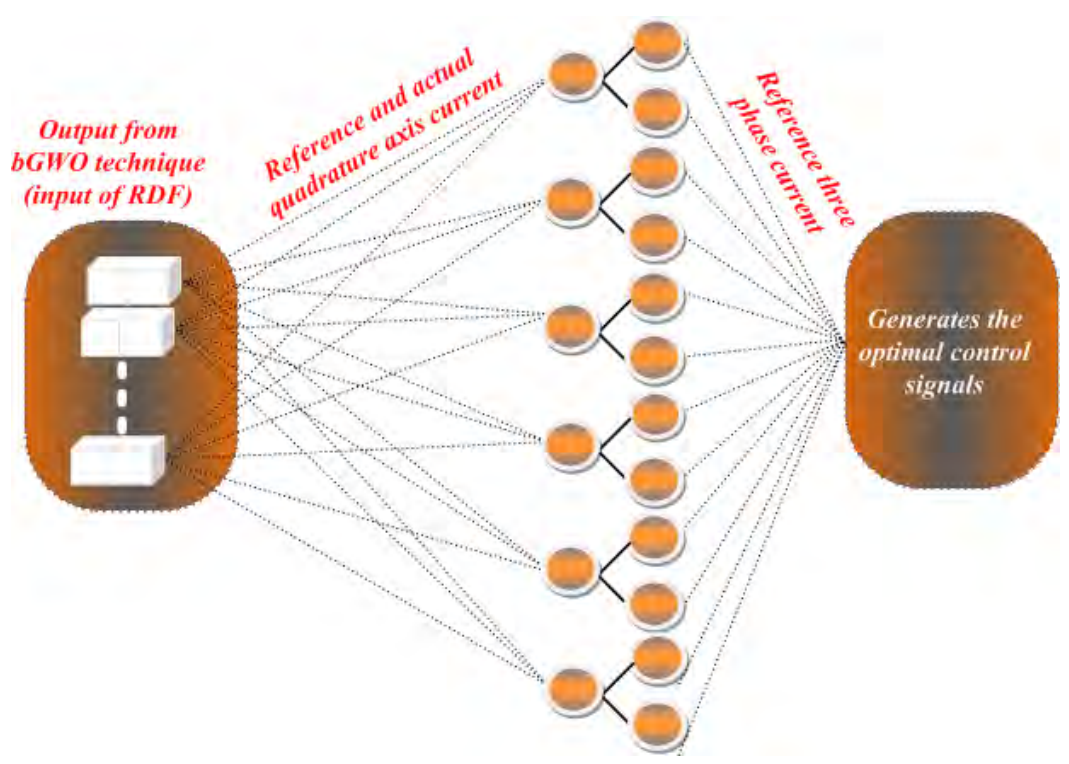

Figure 4. Control signals generation using RDF technique

\section{Simulation Results and Discussion for the Performance Analysis of QZSI Fed IM Drive System}

In this section, the simulation results and discussion for the performance analysis of QZSI fed IM drive system is analyzed. For the operation of IM, the outcome of the inverter is used. The input of the proposed strategy is the speed and three phase current of IM. With the help of input parameters like actual speed of IM and reference speed, the PI controller gain parameters are optimized using the binary version of Grey Wolf Optimization (bGWO) technique. In order to train the random decision forest (RDF), the PI controller output like reference quadrature axis current and actual quadrature axis current is chosen. By utilizing the random decision forest (RDF), the reference three phase current has been generated. By the actual and reference three phase current, the control pulses are generated at the final stage. In order to operate the insulated gate bi-polar transistor (IGBT) the control pulses are utilized. In the MATLAB/Simulink working platform, the performance of the proposed and the existing techniques are analyzed. The existing techniques such as Artificial Neural Network (ANN), Particle Swarm Optimization (PSO), Particle Swarm Optimization-Support Vector Machine (PSO-SVM) and Gravitational Search Algorithm-Support Vector Machine (GSA-SVM). The performance analysis is executed under two case studies. They are:

\subsection{Analysis of Cases}

\subsubsection{Case A: Demand torque Variation from ( 0 to $2 \& 2$ to} 2.5)

In this section, the performance analysis of proposed and the existing techniques under demand torque variation from ( 0 to $2 \& 2$ to 2.5$)$ is performed. The performance analysis of actual and reference demand torque variation is depicted in Fig 5. By clearly watching the Fig 5, the actual and reference demand torque varied in the time duration of 0 to $2 \mathrm{sec}$ with the actual demand torque of 300 to $50 \mathrm{NM}$, reference demand torque of 100 to $200 \mathrm{NM}$. Also in the time duration of 2 to $2.5 \mathrm{sec}$, the actual demand torque of 50 to $250 \mathrm{NM}$ and the reference demand torque of $200 \mathrm{NM}$. Fig 6 shows the performance analysis of speed of IM and its comparison with existing techniques, current and DC voltage. Fig 6 (a) depicts the graph of speed of IM. By observing, the speed of IM varied at the time instant of 0 to $2.5 \mathrm{sec}$ from the speed range of 0 to $120 \mathrm{rpm}$. Fig 6 (b) clearly concludes that the proposed technique has the optimal value than the existing techniques in terms of IM speed. Fig 6 (c) delineates the performance of current under case B. The current in the system varied at the initial condition with interruption in the time instant of 0 to $1 \mathrm{sec}$. Fig 6 (d) shows the DC voltage of proposed strategy. The DC voltage of the system varied and noticed in the time instant of 0 to $2.5 \mathrm{sec}$.

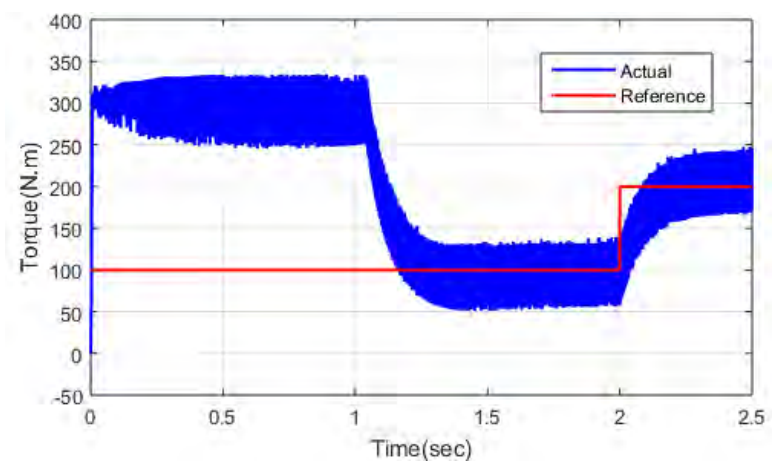

Figure 5. Performance analysis of actual and reference demand torque variation 


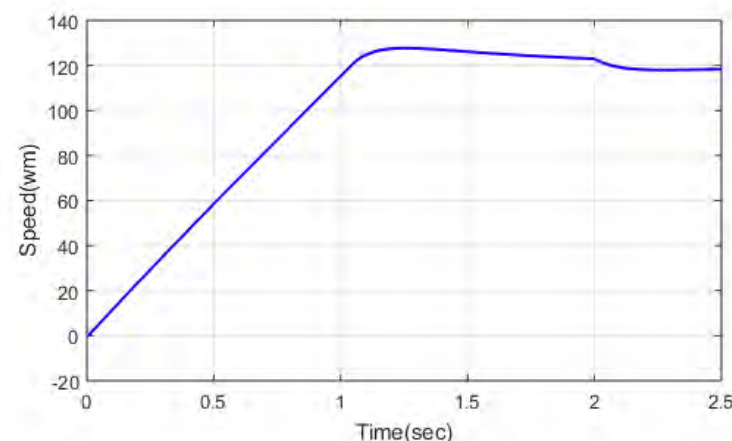

(a)

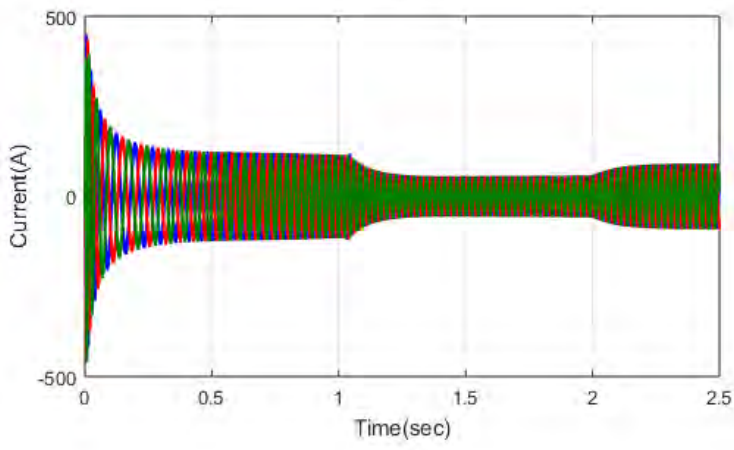

(c)

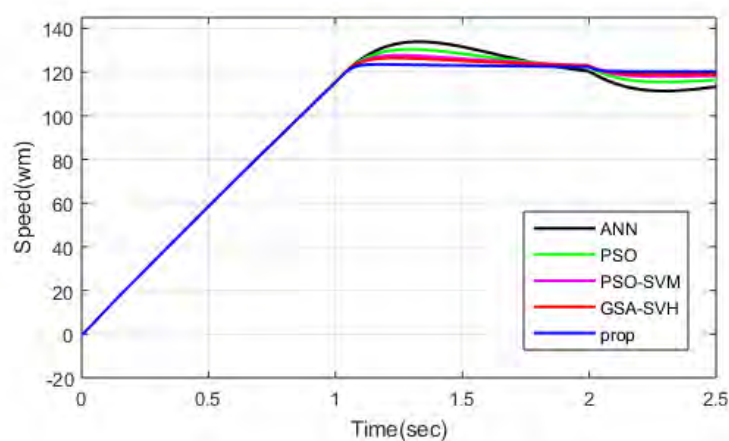

(b)

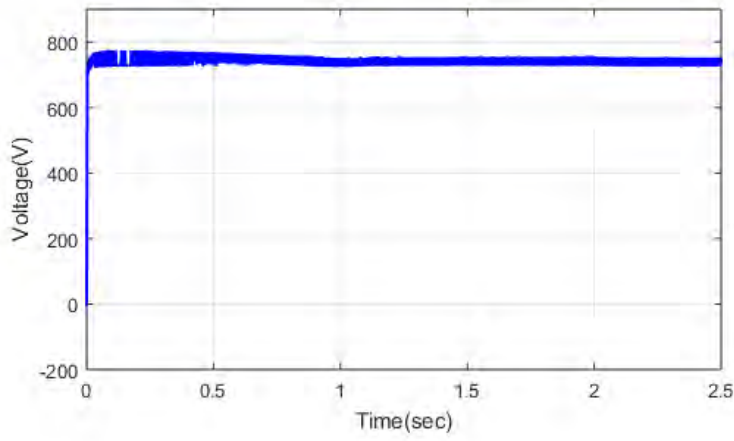

(d)

Figure 6. Performance analysis of (a) speed (b) speed comparison (c) current (d) DC voltage

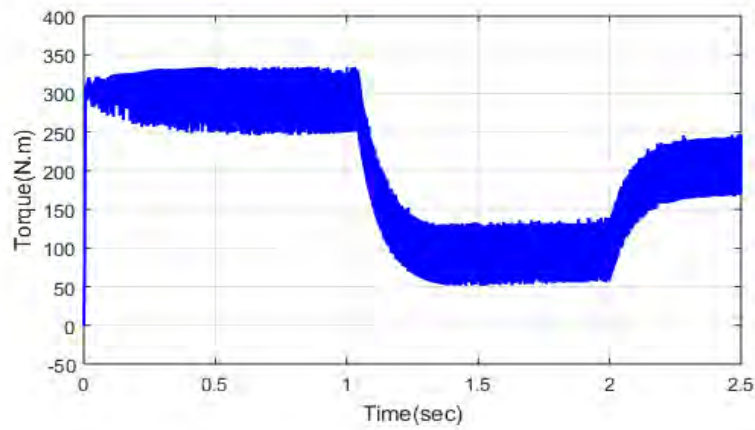

(a)

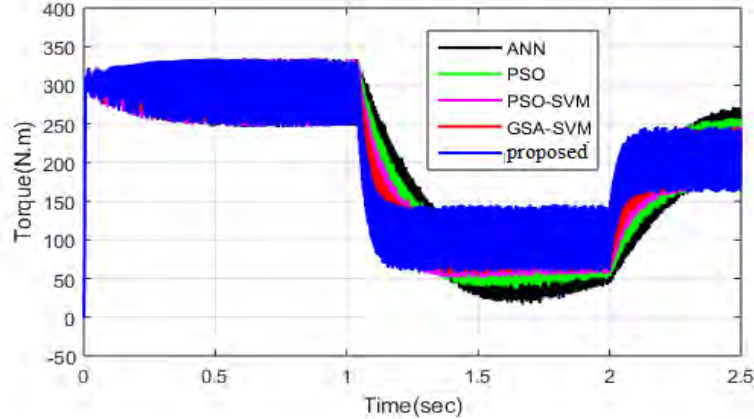

(b)

Figure 7. Performance analysis of (a) torque (b) torque comparison

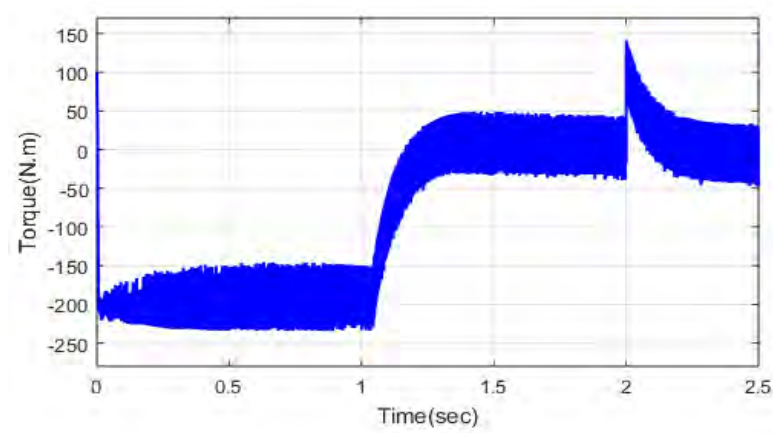

(a)

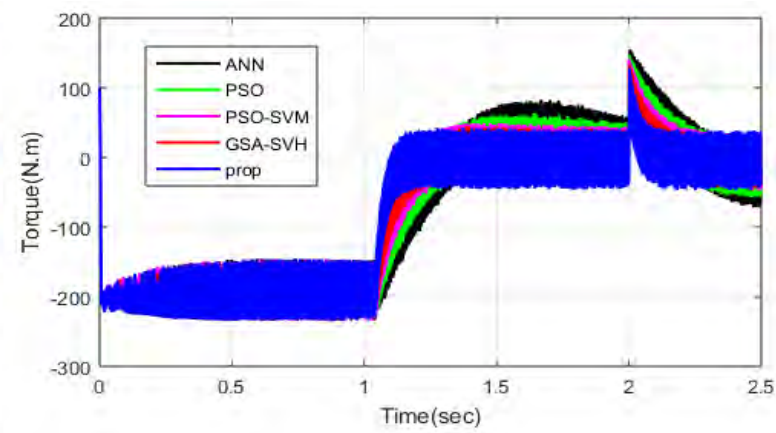

(b)

Figure 8. Performance analysis of (a) error torque (b) error torque comparison 


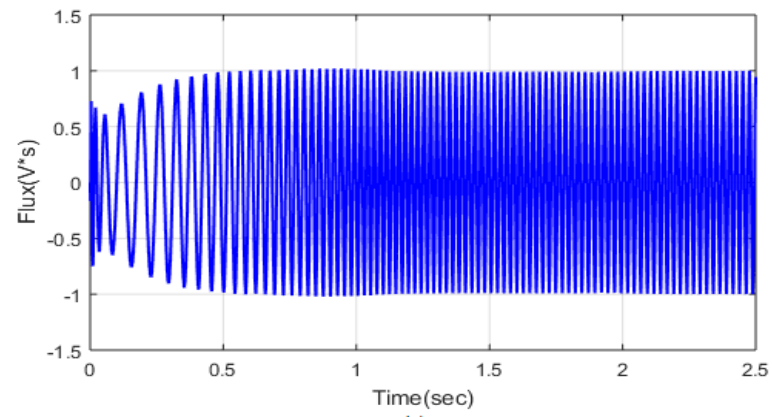

(a)

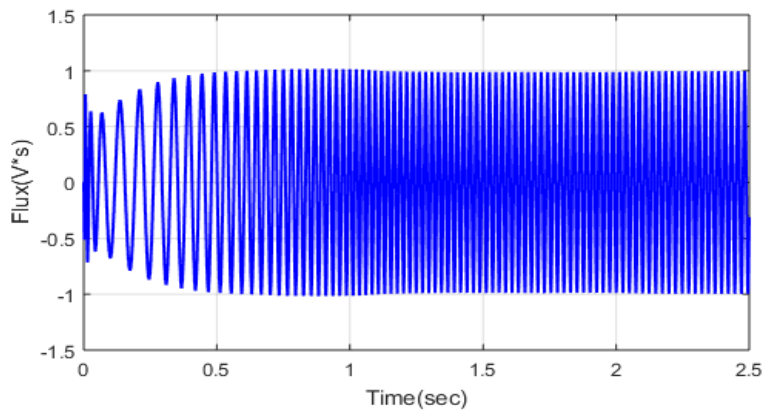

(b)

Figure 9. Performance analysis of stator flux (a) d-axis (b) q-axis

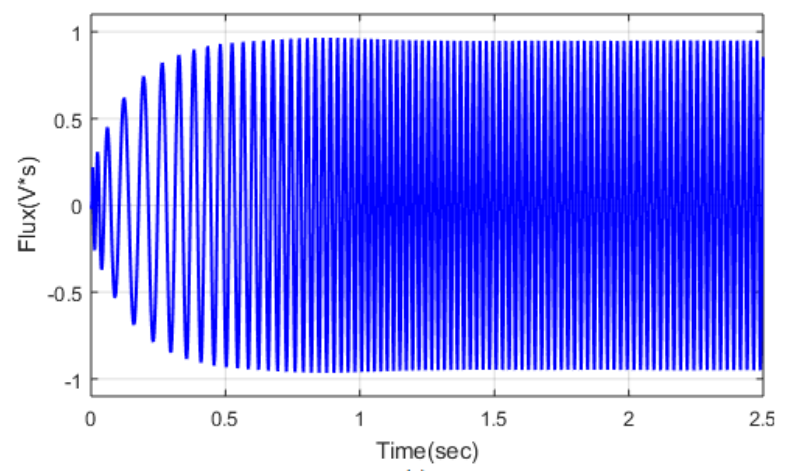

(a)

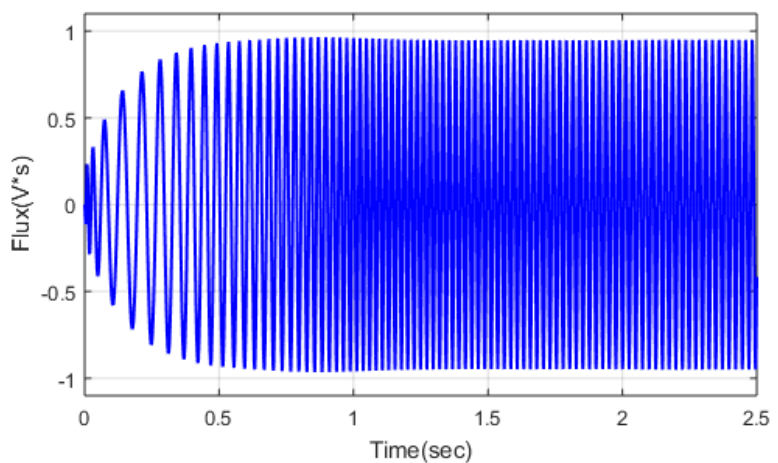

(b)

Figure 10. Performance analysis of rotor flux (a) d-axis (b) q-axis

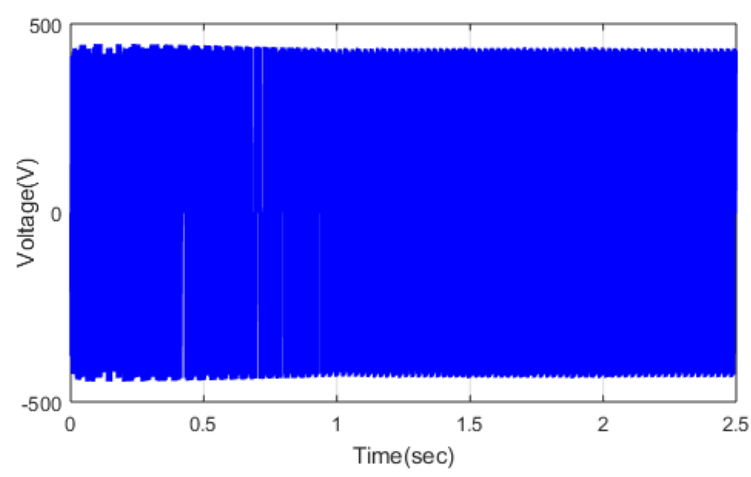

(a)

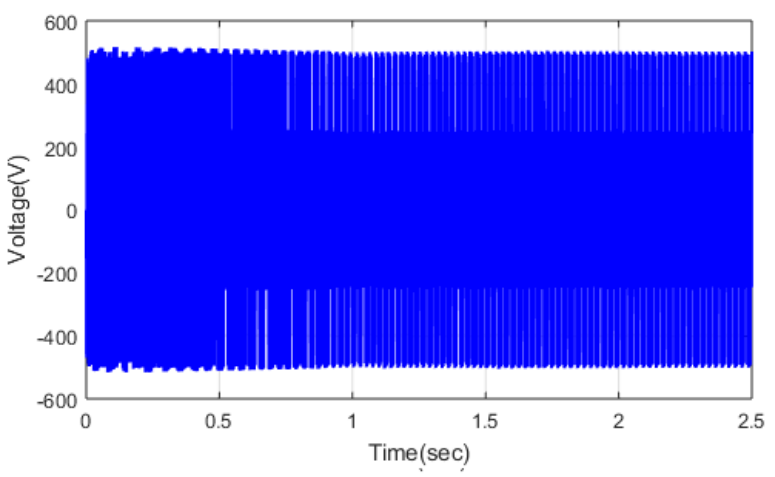

(b)

Figure 11. Performance analysis of stator voltage (a) d-axis (b) q-axis 


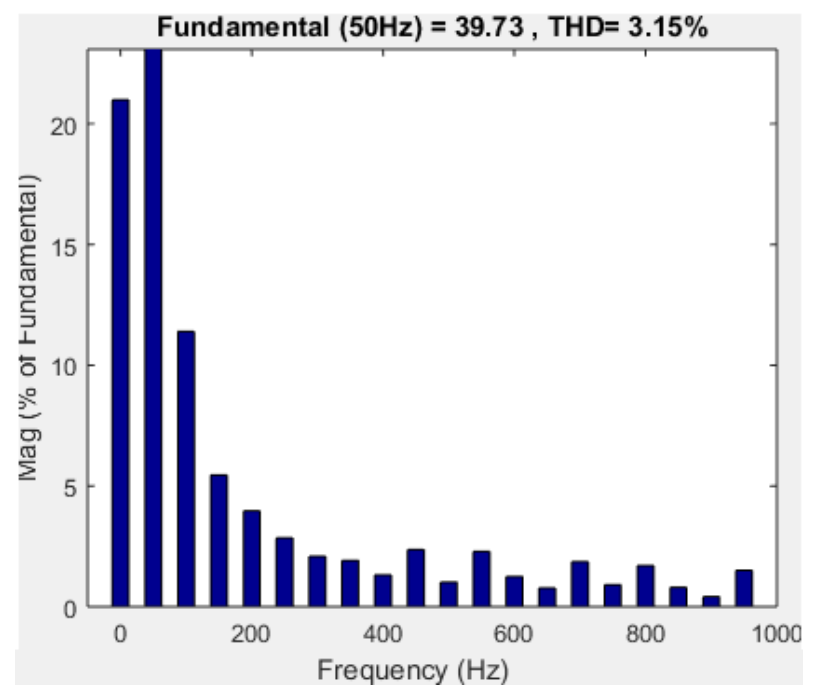

Figure 12. THD Performance of proposed strategy

Fig 7 depicts the performance analysis graph of torque and the comparison with existing techniques. By clearly watching the Fig 7 (a), the torque of the IM is varied with the time instant of optimally from 0 to 2 and 2 to $2.5 \mathrm{sec}$ with torque variation of 300 to $50 \mathrm{Nm}$ and 50 to $250 \mathrm{Nm}$. But the existing techniques achieve power torque in the IM which is graphically expressed in Fig 7 (b). Fig 8 depicts the performance analysis graph of error torque and the comparison with existing techniques. By clearly watching the Fig 8 (a), the error torque of the IM is varied with the time instant of optimally from 0 to 2 and 2 to $2.5 \mathrm{sec}$ with the torque value of $140 \mathrm{Nm}$. But the existing techniques achieve power torque in the IM which is graphically expressed in Fig 8 (b). Fig 9 shows the performance analysis graph of stator flux in the $\mathrm{d}$ and q-axis. By clearly watching the Fig 9 (a), the stator flux in the d-axis is varied with the time instant of 0 to 1 . Fig 9 (b), the stator flux in the q-axis is varied with the time instant of 0 to 1 . Fig 10 shows the performance analysis graph of rotor flux in the $\mathrm{d}$ and q-axis. By clearly watching the Fig 10 (a), the rotor flux in the d-axis is varied with the time instant of 0 to 1 . Fig 10 (b), the rotor flux in the q-axis is varied with the time instant of optimally from 0 to 1 . Fig 11 shows the performance analysis graph of stator voltage in the $\mathrm{d}$ and q-axis. By clearly watching the Fig 11 (a), the stator voltage in the d-axis is varied with the time instant of 0 to 2.5. Fig $11(\mathrm{~b})$, the stator voltage in the $\mathrm{q}$-axis is varied with the time instant of 0 to 2.5. THD performance of the proposed strategy is delineated in Fig 12. By clearly watching the Fig 12, the THD value of proposed strategy achieves $3.15 \%$ under case $\mathrm{A}$.

\subsubsection{Case B: Demand torque Variation from (0 to $1.5 \&$ 1.2 to 2.5 )}

In this section, the performance analysis of proposed and the existing techniques under demand torque variation from ( 0 to $1.5 \& 1.2$ to 2.5$)$ is performed. The performance analysis of actual and reference demand torque variation is depicted in Fig 13. By clearly watching the Fig 13, the actual and reference demand torque varied in the time duration of 0 to $1.5 \mathrm{sec}$ with the actual demand torque of 300 to $0 \mathrm{NM}$, reference demand torque of 50 to $100 \mathrm{NM}$. Also in the time duration of 1.5 to $2.5 \mathrm{sec}$, the actual demand torque of 0 to $150 \mathrm{NM}$ and the reference demand torque of $100 \mathrm{NM}$. Fig 14 shows the performance analysis of speed of IM and its comparison with existing techniques, current and DC voltage. Fig 14 (a) depicts the graph of speed of IM. By observing, the speed of IM varied at the time instant of 0 to $2.5 \mathrm{sec}$ from the speed range of 0 to 125 rpm. Fig 14 (b) clearly concludes that the proposed technique has the optimal value than the existing techniques in terms of IM speed. Fig 14 (c) delineates the performance of current under case B. The current in the system varied at the initial condition with interruption in the time instant of 0 to $0.8 \mathrm{sec}$. Fig 14 (d) shows the DC voltage of proposed strategy. The DC voltage of the system varied and noticed in the time instant of 0 to $2.5 \mathrm{sec}$.

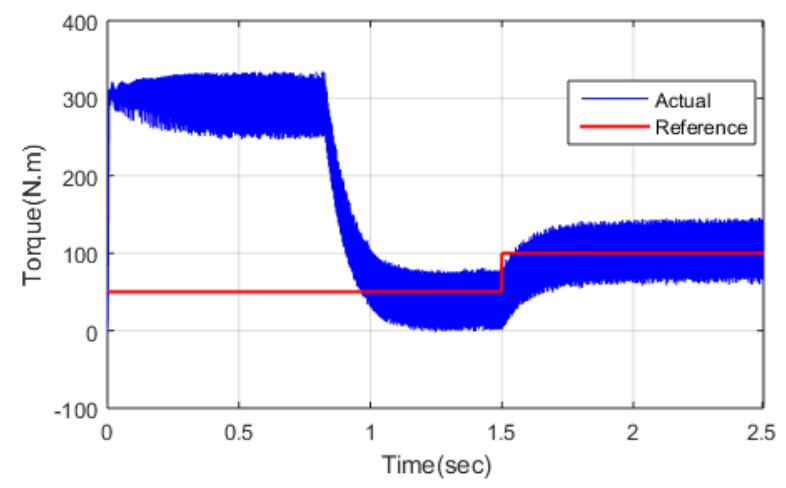

Figure 13. Performance analysis of actual and reference demand torque variation 


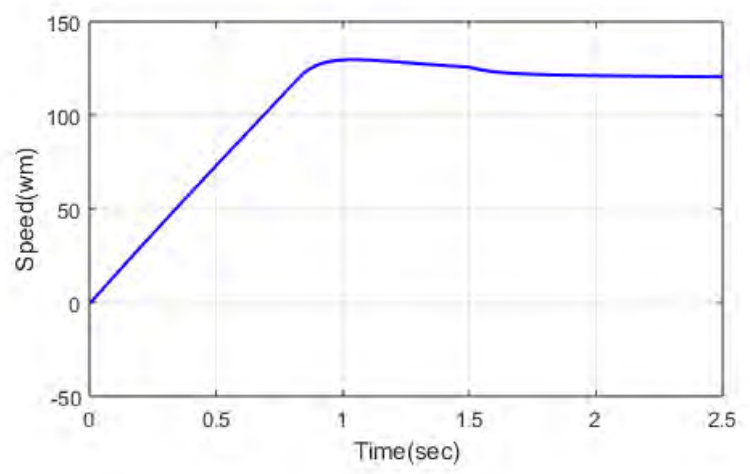

(a)

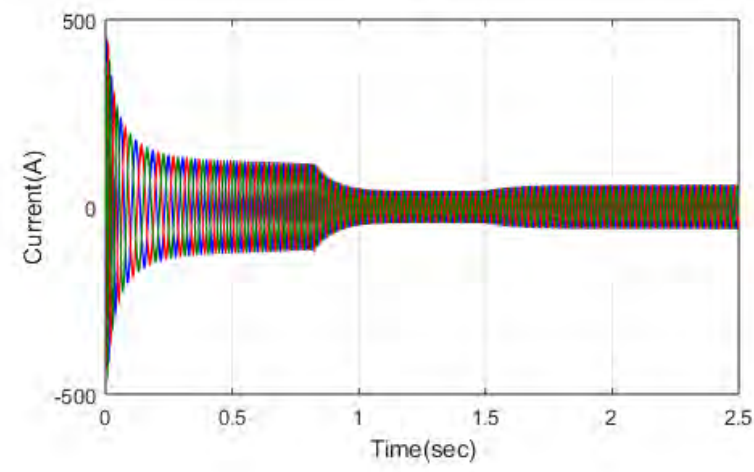

(c)

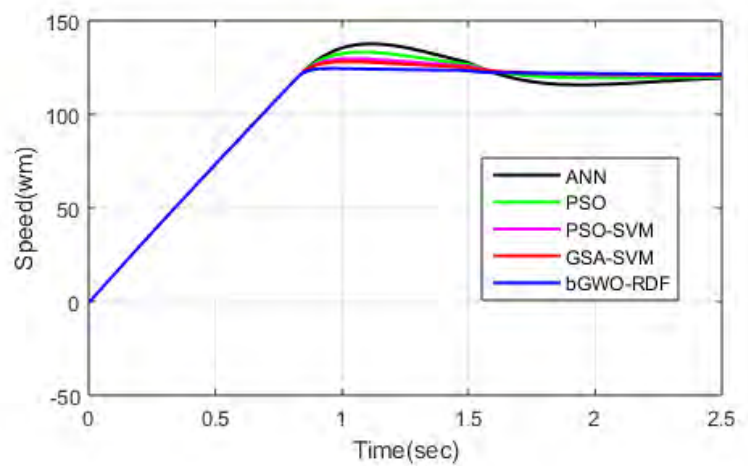

(b)

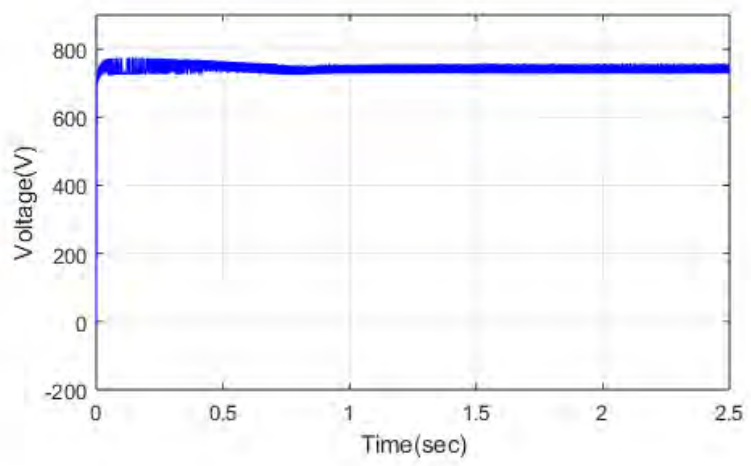

(d)

Figure 14. Performance analysis of (a) speed (b) speed comparison (c) current (d) DC voltage

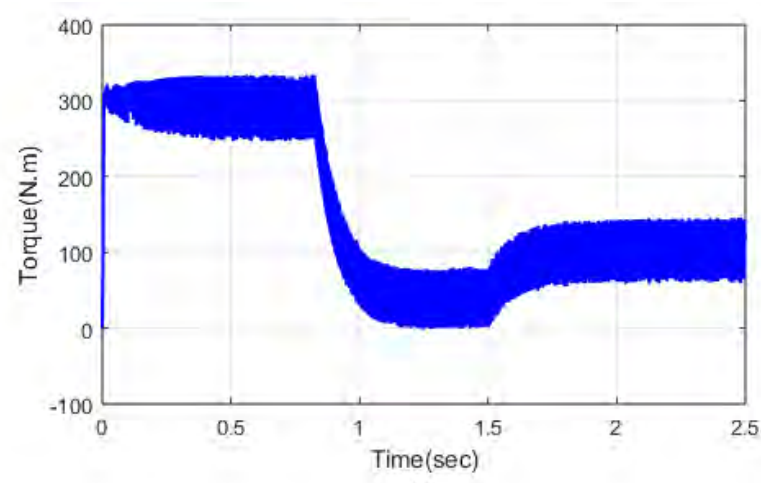

(a)

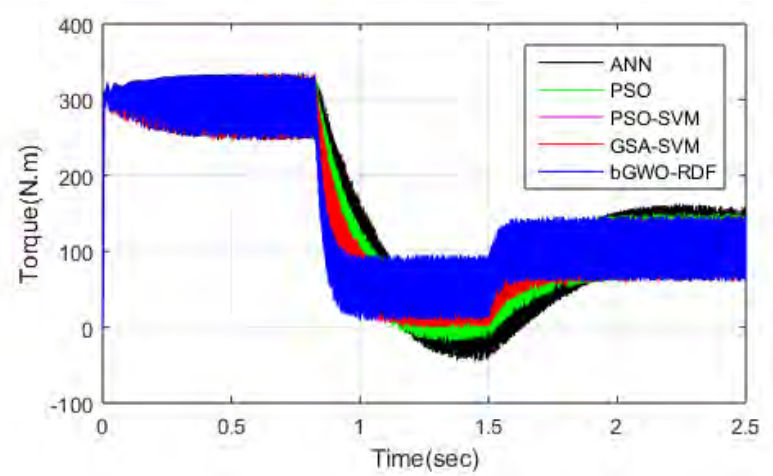

(b)

Figure 15. Performance analysis of (a) torque (b) torque comparison

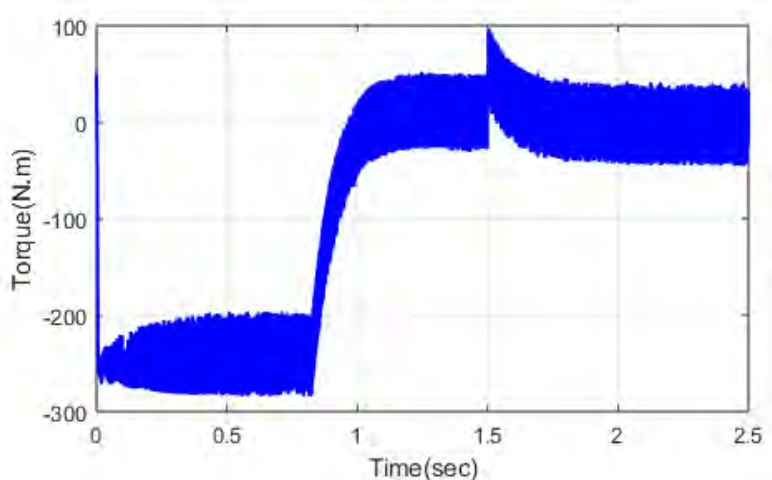

(a)

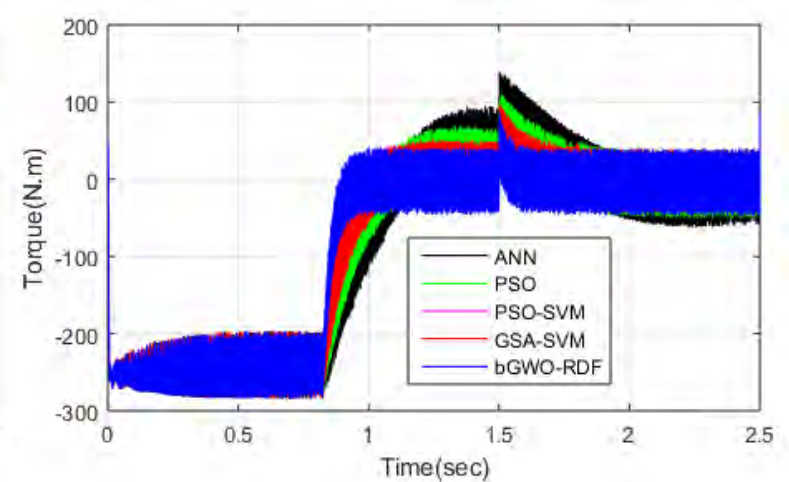

(b)

Figure 16. Performance analysis of (a) error torque (b) error torque comparison 


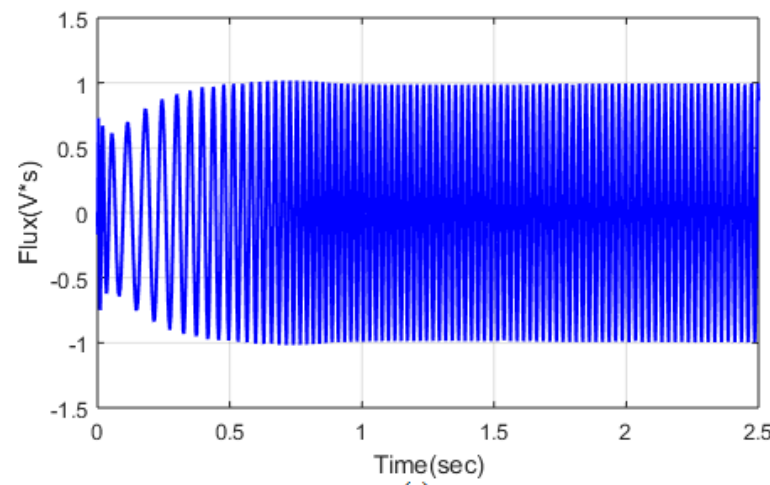

(a)

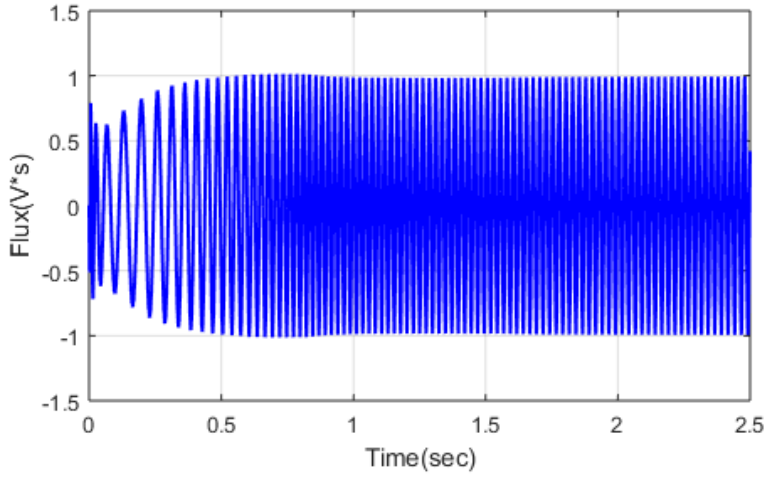

(b)

Figure 17. Performance analysis of stator flux (a) d-axis (b) q-axis

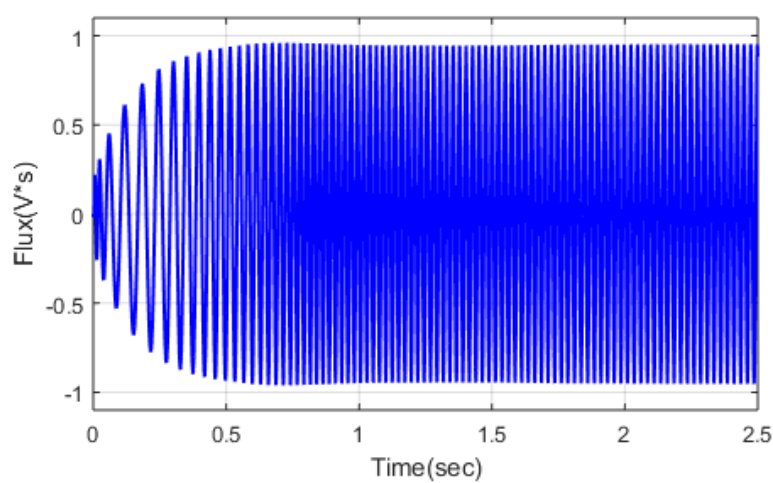

(a)

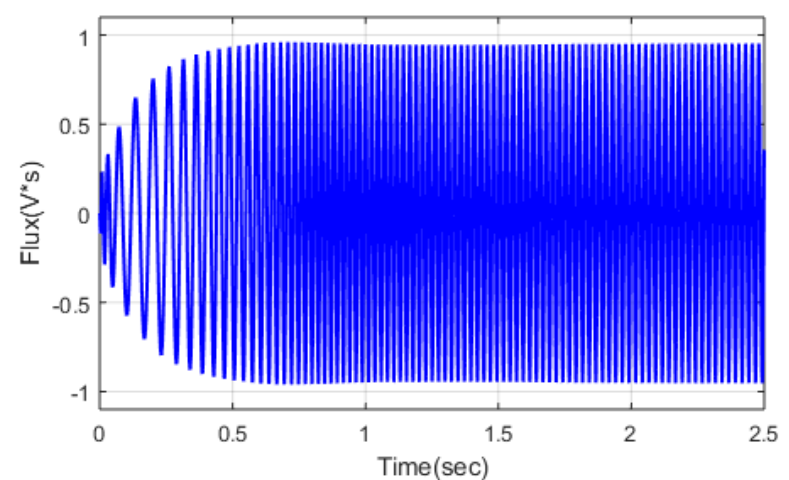

(b)

Figure 18. Performance analysis of rotor flux (a) d-axis (b) q-axis

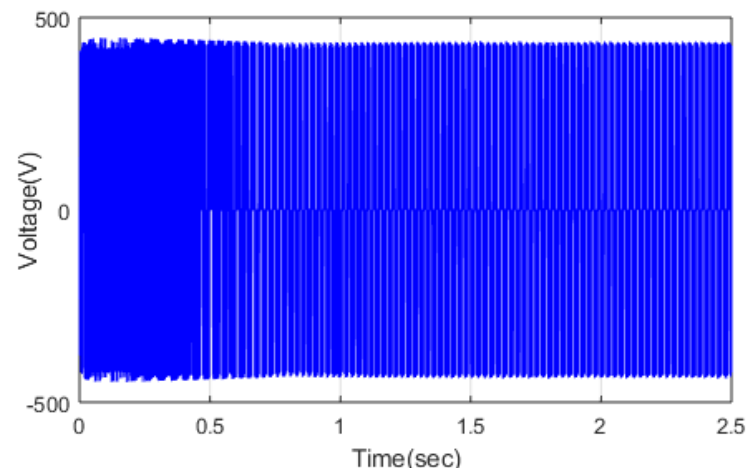

(a)

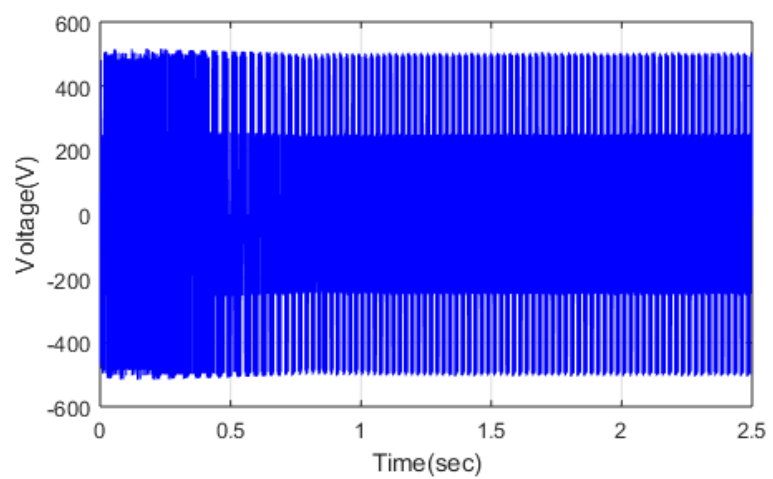

(b)

Figure 19. Performance analysis of stator voltage (a) d-axis (b) q-axis 


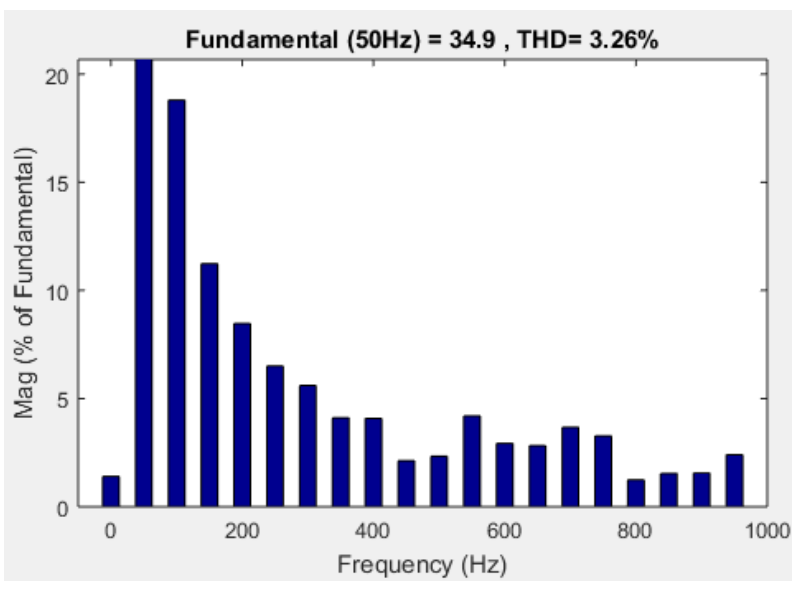

Figure 20. THD Performance of proposed strategy

Fig 15 depicts the performance analysis graph of torque and the comparison with existing techniques. By clearly watching the Fig 15 (a), the torque of the IM is varied with the time instant of 0 to 1.5 and 1.5 to $2.5 \mathrm{sec}$. But the existing techniques achieve power torque in the IM which is graphically expressed in Fig 15 (b). Fig 16 depicts the performance analysis graph of error torque and the comparison with existing techniques. By clearly watching the Fig 16 (a), the error torque of the IM is varied with the time instant of 0 to 1.5 and 1.5 to $2.5 \mathrm{sec}$ with the torque value of $100 \mathrm{Nm}$. But the existing techniques achieve power torque in the IM which is graphically expressed in Fig 16 (b). Fig 17 shows the performance analysis graph of stator flux in the $\mathrm{d}$ and q-axis. By clearly watching the Fig 17 (a), the stator flux in the d-axis is varied with the time instant of 0 to 1 . Fig 17 (b), the stator flux in the q-axis is varied with the time instant from 0 to 1 . Fig 18 shows the performance analysis graph of rotor flux in the $\mathrm{d}$ and q-axis. By clearly watching the Fig 18 (a), the rotor flux in the $\mathrm{d}$-axis is varied with the time instant of 0 to 1 . Fig 18 (b), the rotor flux in the q-axis is varied with the time instant of 0 to 1 . Fig 19 shows the performance analysis graph of stator voltage in the $\mathrm{d}$ and q-axis. By clearly watching the Fig 19 (a), the stator voltage in the d-axis is varied with the time instant of 0 to 2.5 . Fig 19 (b), the stator voltage in the $\mathrm{q}$-axis is varied with the time instant from 0 to 2.5. THD performance of the proposed strategy is delineated in Fig 20. By clearly watching the Fig 20, the THD value of proposed strategy achieves $3.26 \%$ under case B. The performance evaluation of proposed and the existing techniques is given in the next section.

\subsection{Performance Evaluation in Terms of Various Metrics}

In this section, the performance evaluation of proposed and the existing techniques in terms of various metrics under all cases is inspected. Various metrics are statistical measures, efficiency, ripples reduction, time domain parameters, THD reduction and elapsed time. The results are as follows:

Table 1. Statistical measures of proposed and existing techniques under Case A

\begin{tabular}{|c|c|c|c|}
\hline Solution techniques & Mean & Median & Standard deviation \\
\hline Proposed & 1.3789 & 1.3269 & 0.1004 \\
\hline GSA-SVM & 1.4930 & 1.4410 & 0.1132 \\
\hline PSO-SVM & 1.5334 & 1.4704 & 0.1154 \\
\hline PSO & 1.6527 & 1.5802 & 0.1256 \\
\hline ANN & 1.4261 & 1.9161 & 0.3621 \\
\hline
\end{tabular}

Table 2. Statistical measures of proposed and exiting techniques under Case B

\begin{tabular}{|c|c|c|c|}
\hline Solution techniques & Mean & Median & Standard deviation \\
\hline Proposed & 1.3453 & 1.2951 & 0.0893 \\
\hline GSA-SVM & 1.4411 & 1.3757 & 0.1047 \\
\hline PSO-SVM & 1.5431 & 1.4888 & 0.1150 \\
\hline PSO & 1.6399 & 1.5938 & 0.1288 \\
\hline ANN & 1.7456 & 1.9655 & 0.2637 \\
\hline
\end{tabular}

Table 3. Comparison of proposed technique with existing techniques in terms of efficiency

\begin{tabular}{|c|c|c|c|c|}
\hline \multicolumn{5}{|c|}{ Efficiency $(\%)$} \\
\hline \multirow{2}{*}{$\begin{array}{l}\text { Solution } \\
\text { Techniques }\end{array}$} & \multicolumn{4}{|c|}{ Cases } \\
\hline & \multicolumn{2}{|c|}{ Case A } & \multicolumn{2}{|c|}{ Case B } \\
\hline ANN & 32.1653 & 56.2453 & 65.3232 & 44.3956 \\
\hline PSO & 66.1152 & 38.5231 & 25.1239 & 66.9872 \\
\hline PSO-SVM & 80.2357 & 81.2336 & 77.7259 & 72.6358 \\
\hline GSA-SVM & 81.1182 & 73.0023 & 79.9648 & 89.9907 \\
\hline Proposed Technique & 97.3975 & 95.213 & 93.978 & 91.515 \\
\hline
\end{tabular}

Table 4. Comparison of proposed technique with existing techniques in terms of ripples

\begin{tabular}{|c|c|c|c|c|c|c|c|c|c|c|}
\hline \multirow{3}{*}{ Parameters } & \multicolumn{9}{|c|}{ Solution Techniques } \\
\cline { 2 - 14 } & \multicolumn{2}{|c|}{ ANN } & \multicolumn{2}{|c|}{ PSO } & \multicolumn{2}{c|}{ PSO-SVM } & \multicolumn{2}{c|}{ GSA-SVM } & \multicolumn{2}{c|}{ Proposed Technique } \\
\cline { 2 - 13 } & Min (\%) & Max (\%) & Min (\%) & Max (\%) & Min (\%) & Max (\%) & Min (\%) & Max (\%) & Min (\%) & Max (\%) \\
\hline Torque ripples & 1.9 & 17.369 & 0.50 & 5 & 0.4 & 4 & 0.28 & 3.2 & 0.21 & 0.91 \\
\hline Stator flux ripples & 0.887 & 5.97 & 0.04 & 4.30 & 0.012 & 11.31 & 0.904 & 9.21 & 0.51 & 1.1 \\
\hline
\end{tabular}


Table 5. Comparison of proposed technique with existing techniques in terms of time domain parameters

\begin{tabular}{|c|c|c|c|}
\hline \multirow{2}{*}{$\begin{array}{c}\text { Solution } \\
\text { Techniques }\end{array}$} & $\begin{array}{c}\text { Rise time } \\
(\mathrm{sec})\end{array}$ & $\begin{array}{c}\text { Settling time } \\
(\mathrm{sec})\end{array}$ & $\begin{array}{c}\text { Steady state } \\
\text { error (volts) }\end{array}$ \\
\cline { 2 - 4 } ANN & 0.837 & 1.96 & 21 \\
\hline PSO & 0.751 & 1.73 & 18.5 \\
\hline PSO-SVM & 0.727 & 1.33 & 19.73 \\
\hline GSA-SVM & 0.73 & 1.4 & 15 \\
\hline Proposed & 0.65 & 0.81 & 8.1 \\
\hline
\end{tabular}

Table 6. Comparison of proposed technique with existing techniques in terms of THD reduction for Case A and B

\begin{tabular}{|c|c|c|}
\hline \multirow{2}{*}{ Solution Techniques } & \multicolumn{2}{|c|}{ THD (\%) } \\
\cline { 2 - 3 } & Case A & Case B \\
\hline bGWO-RDF & 3.15 & 3.26 \\
\hline GSA-SVM & 3.25 & 3.48 \\
\hline PSO-SVM & 3.47 & 3.92 \\
\hline PSO & 3.86 & 4.21 \\
\hline ANN & 4.7 & 4.85 \\
\hline
\end{tabular}

Table 7. Elapsed time comparison

\begin{tabular}{|c|c|}
\hline Solution Techniques & Elapsed time \\
\hline ANN & 6.875 \\
\hline PSO & 5.112 \\
\hline PSO-SVM & 4.867 \\
\hline GSA-SVM & 4.5 \\
\hline Proposed & 4.12 \\
\hline
\end{tabular}

In case $A$, table 1 shows the statistical measure of proposed and existing techniques. Table 1 includes the mean, median and standard deviation. Here, the mean, the median and standard deviation of the proposed technique is lower than the other techniques. In case B, table 2 shows the statistical measures of proposed and existing techniques. Table 2 includes mean, median and the standard deviation. Here, the average value, the median and standard deviation of the proposed technique is lower than other solution techniques. In table 3 used to tabulate the comparison of efficiency under two cases with proposed and existing techniques. Table 3 clearly explains the effectiveness of the proposed technique in all the cases with optimal efficiency results. Efficiency is the production of energy output, divided by the input of energy, and expressed as a percentage. Comparison of the proposed technique with existing techniques in terms of waves is tabulated in Table 4. Comparison of the proposed technique with existing techniques in terms of time domain parameters is shown in Table 5. Table 6 shows the THD value obtained by proposed under two cases and compared with existing techniques. Comparison of time elapsed is shown in Table 7. Based on the above considerations, the performances of the proposed method and existing techniques are analyzed using the torque and stator flow waves, the time domain parameters and elapsed time obtained by the system drive. From the evaluations, the effectiveness of the proposed method is determined. Efficiency is evaluated based on the overall performance of the IM drive system powered by QZSI. By using the proposed strategy, the IM drive system powered by QZSI achieves a better speed response with a lower error compared to that of other controllers. From the previous analysis, the performance of the proposed strategy is much higher in all cases by reducing ripples, efficiency and statistical measures

\section{Conclusions}

In this dissertation, a hybrid strategy of bGWO and RDF technique is designed for the performance analysis of QZSI fed IM drive system. By utilizing the proposed hybrid strategy, the PI controller gain parameters are optimized with help of bGWO technique. By then the RDF technique is trained well and the three phase reference current is optimally generated. Subsequently the optimal control pulses are generated and the performance of the QZSI fed IM drive system works optimally. The proposed hybrid strategy based QZSI fed IM drive system is executed in the MATLAB/Simulink working platform. Under two cases, the proposed and the existing techniques are evaluated. From the simulation results, the proposed method successfully decreased the THD of the stator current under case $\mathrm{A}$ and $\mathrm{B}$ is $3.15 \%$ and $3.26 \%$ and eradicates the oscillations present in the motor torque and speed response. It is examined that the proposed hybrid strategy is highly preferable to improve the presentation of the IM. At last, the comparison results have confirmed that the proposed hybrid strategy is well efficient technique to the other solution techniques.

\section{REFERENCES}

[1] A. Abdelhakim, P. Davari, F. Blaabjerg and P. Mattavelli, Switching Loss Reduction in the Three-Phase Quasi-Z-Source Inverters Utilizing Modified Space Vector Modulation Strategies, IEEE Transactions on Power Electronics, vol. 33, no. 5, pp. 4045-4060, 2018.

[2] M. Zdanowski, D. Peftitsis, S. Piasecki and J. Rabkowski, On the Design Process of a 6-kVA Quasi-Z-inverter Employing $\mathrm{SiC}$ Power Devices, IEEE Transactions on Power Electronics, vol. 31, no. 11, pp. 7499-7508, 2016.

[3] A. Battiston, E. Miliani, S. Pierfederici and F. Meibody-Tabar, A Novel Quasi-Z-Source Inverter Topology with Special Coupled Inductors for Input Current Ripples Cancellation, IEEE Transactions on Power Electronics, vol. 31, no. 3, pp. 2409-2416, 2016.

[4] F. Guo, L. Fu, C. Lin, C. Li, W. Choi and J. Wang, Development of an $85-\mathrm{kW}$ Bidirectional Quasi-Z-Source 
Inverter With DC-Link Feed-Forward Compensation for Electric Vehicle Applications, IEEE Transactions on Power Electronics, vol. 28, no. 12, pp. 5477-5488, 2013.

[5] M. Shen and F. Peng, Operation Modes and Characteristics of the Z-Source Inverter with Small Inductance or Low Power Factor, IEEE Transactions on Industrial Electronics, vol. 55, no. 1, pp. 89-96, 2008.

[6] T. Kayiranga, H. Li, X. Lin, Y. Shi and H. Li, Abnormal Operation State Analysis and Control of Asymmetric Impedance Network-Based Quasi-Z-Source PV Inverter (AIN-qZSI), IEEE Transactions on Power Electronics, vol. 31, no. 11, pp. 7642-7650, 2016.

[7] P. Loh, D. Vilathgamuwa, Y. Lai, G. Chua and Y. Li, Pulse-Width Modulation of Z-Source Inverters, IEEE Transactions on Power Electronics, vol. 20, no. 6, pp. 1346-1355, 2005.

[8] F.Z. Peng, A. Joseph, J. Wang, M. Shen, L. Chen, Z. Pan, E. Ortiz-Rivera, Y. Huang, Z-Source Inverter for Motor Drives, IEEE Transactions on Power Electronics, vol. 20, no. 4, pp. 857-863, 2005.

[9] A. Ba-Razzouk, A. Cheriti, G. Olivier and P. Sicard, Field-oriented control of induction motors using neural-network decouplers, IEEE Transactions on Power Electronics, vol. 12, no. 4, pp. 752-763, 1997.

[10] H. Sathishkumar and S. Parthasarathy, A novel neural network intelligent controller for vector controlled induction motor drive, Energy Procedia, vol. 138, pp. 692-697, 2017.

[11] M. Abido, "Optimal design of power-system stabilizers using particle swarm optimization", IEEE Transactions on Energy Conversion, vol. 17, no. 3, pp. 406-413, 2002.

[12] S. Panda, N. Padhy and R. Patel, Power-system Stability Improvement by PSO Optimized SSSC-based Damping Controller, Electric Power Components and Systems, vol. 36, no. 5, pp. 468-490, 2008.

[13] H. Mostafa, M. El-Sharkawy, A. Emary and K. Yassin, Design and allocation of power system stabilizers using the particle swarm optimization technique for an interconnected power system, International Journal of Electrical Power \& Energy Systems, vol. 34, no. 1, pp. 57-65, 2012.

[14] Y. Huang, M. Shen, F. Peng and J. Wang, \$Z\$-Source Inverter for Residential Photovoltaic Systems, IEEE Transactions on Power Electronics, vol. 21, no. 6, pp. 1776-1782, 2006.

[15] Fang Zheng Peng, Z-source inverter, IEEE Transactions on Industry Applications, vol. 39, no. 2, pp. 504-510, 2003.

[16] F. Peng, M. Shen and Z. Qian, Maximum Boost Control of the Z-Source Inverter, IEEE Transactions on Power Electronics, vol. 20, no. 4, pp. 833-838, 2005.

[17] Miaosen Shen, Jin Wang, A. Joseph, Fang Zheng Peng, L. Tolbert and D. Adams, Constant boost control of the $\mathrm{Z}$-source inverter to minimize current ripple and voltage stress, IEEE Transactions on Industry Applications, vol. 42, no. 3, pp. 770-778, 2006

[18] S. Yang, F. Peng, Q. Lei, R. Inoshita and Z. Qian, Current-Fed Quasi-Z-Source Inverter With Voltage Buck,
IEEE Transactions on Industry Applications, vol. 47, no. 2 , pp. 882-892, 2011.

[19] A. Hava, R. Kerkman and T. Lipo, Carrier-based PWM-VSI overmodulation strategies: analysis, comparison, and design, IEEE Transactions on Power Electronics, vol. 13, no. 4, pp. 674-689, 1998.

[20] A. Trzynadlowski and S. Legowski, Minimum-loss vector PWM strategy for three-phase inverters, IEEE Transactions on Power Electronics, vol. 9, no. 1, pp. 26-34, 1994.

[21] S. Dong, Q. Zhang, H. Ma and R. Wang, Design for the Interior Permanent Magnet Synchronous Motor Drive System Based on the Z-Source Inverter, Energies, vol. 12, no. 17 , p. $3350,2019$.

[22] M. Muhammad, Z. Rasin, A. Jidin, R.N. Firdaus, Modelling and Simulation of Hybrid Energy Storage for QZSI Inverter Applied in Induction Motor Drive, International Journal of Recent Technology and Engineering, vol. 8, no. 3, pp. 3462-3468, 2019.

[23] A. Panda and R. Pandey, Performance evaluation of controlled QZSI fed five - phase induction motor under voltage sag and interruption, International Transactions on Electrical Energy Systems, 2019.

[24] S. Mythili and K. Thiyagarajah, Z-Source Inverter Fed Induction Motor Drive Control Using Hybrid Methodology, Journal of Circuits, Systems and Computers, vol. 27, no. 03, p. 1850042, 2017.

[25] Mahima Sharma and Mahendra Lalwani, Performance Evaluation of Three-Phase Induction Motor Drive Fed from Z-Source Inverter, International Journal of Applied Engineering Research, vol. 13, no. 8, 2018.

[26] R. Selva Santhose Kumar and S. Girirajkumar, Z-Source Inverter Fed Induction Motor Drive control using Particle Swarm Optimization Recurrent Neural Network, Journal of Intelligent \& Fuzzy Systems, vol. 28, no. 6, pp. 2749-2760, 2015.

[27] Y. Liu, B. Ge and H. Abu-Rub, Modelling and controller design of quasi-Z-source cascaded multilevel inverter-based three-phase grid-tie photovoltaic power system, IET Renewable Power Generation, vol. 8, no. 8, pp. 925-936, 2014

[28] E. Emary, H. Zawbaa and A. Hassanien, Binary grey wolf optimization approaches for feature selection, Neurocomputing, vol. 172, pp. 371-381, 2016.

[29] L. Panwar, S. Reddy K, A. Verma, B. Panigrahi and R. Kumar, Binary Grey Wolf Optimizer for large scale unit commitment problem, Swarm and Evolutionary Computation, vol. 38, pp. 251-266, 2018.

[30] K. Srikanth, L. Panwar, B. Panigrahi, E. Herrera-Viedma, A Sangaiah and G. Wang, Meta-heuristic framework: Quantum inspired binary grey wolf optimizer for unit commitment problem, Computers \& Electrical Engineering, vol. 70, pp. 243-260, 2018.

[31] N. Mittal, U. Singh and B. Sohi, Modified Grey Wolf Optimizer for Global Engineering Optimization, Applied Computational Intelligence and Soft Computing, vol. 2016, pp. 1-16, 2016.

[32] K. Sujatha and D. Shalini Punithavathani, Optimized 
ensemble decision-based multi-focus imagefusion using binary genetic Grey-Wolf optimizer in camera sensor networks, Multimedia Tools and Applications, vol. 77, no. 2, pp. 1735-1759, 2017.

[33] A. Smith, Image segmentation scale parameter optimization and land cover classification using the Random Forest algorithm, Journal of Spatial Science, vol. 55, no. 1, pp. 69-79, 2010.

[34] A. Sankaran, A. Jain, T. Vashisth, M. Vatsa and R. Singh, Adaptive latent fingerprint segmentation using feature selection and random decision forest classification, Information Fusion, vol. 34, pp. 1-15, 2017.

[35] Jiawei Han, Yanheng Liu and Xin Sun, A scalable random forest algorithm based on MapReduce, 2013 IEEE 4th International Conference on Software Engineering and Service Science, 2013.

[36] S. Fletcher and M. Islam, A Differentially Private Random Decision Forest Using Reliable Signal-to-Noise Ratios, AI 2015: Advances in Artificial Intelligence, pp. 192-203, 2015.

[37] W. Chen, S. Zhang, R. Li and H. Shahabi, Performance evaluation of the GIS-based data mining techniques of best-first decision tree, random forest, and naïve Bayes tree for landslide susceptibility modeling, Science of The Total Environment, vol. 644, pp. 1006-1018, 2018. 